\title{
Experience of Pandemic Influenza A (H1N1) 2009 at Dhaka Medical College Hospital
}

(J Bangladesh Coll Phys Surg 2010; 28: 63)

Influenza pandemic is not a new phenomenon to the world. The recent outbreak of Pandemic Influenza H1N1 2009, is a newly packaged from of the good old Influenza A virus (H3N2) swept across the world! It's a triple reassortment virus: Which means that it is a combination of the classical Swine HIN2, Human $\mathrm{H} 3 \mathrm{~N} 2$ and Avian influenza viruses known as the North American Swine H3N2 and H1N2 that later converted into the 2009 Human H1N1 virus. The World Health Organization has stopped using the term "swine flu" to avoid confusion over the danger posed by pigs. The proper name is "Pandemic (HIN1) 2009 Influenza".

The first case of 2009 pandemic influenza A (H1N1) virus infection in Bangladesh was documented on June $18^{4}$ Subsequently, persons with suspected cases of infection and contacts of those with suspected infection were tested. Individuals in whom infection was confirmed were hospitalized and quarantined, and some of them were closely pbserved for the purpose of investigating the nature and duration of the disease. In Dhaka Medical College Hospital there were 28 admitted patients in flu ward and 2335 registered suspected H1N1 influenza cases were attended in flue corner but 833 highly suspected cases were recorded in case record form. We describe the clinical and epidemiological characteristics of 28 indoor (flu ward) and 833 outdoor (flu corner) patients. Most of them were in between 20 to 30 years age group. Among 833 outdoor patients 611(73.34\%) were male and $222(26.65 \%)$ were female. 354 $(42.49 \%)$ patients were student, $195(23.40 \%)$ were service holder. No patients (indoor) had any serious underlying medical conditions. Indoor patients presented with mostly fever $(92.85 \%)$, Rhinorrhea
(71.42\%), shortness of breath $(89.28 \%)$ and cough $(64.28 \%)$. Where Out of the 833 outdoor patients $59 \mathrm{~b}(71.54 \%)$ patients had fever, 585(70.229b) had cough, 410(49.21\%) had Rhinorrhea and 314 (37.69\%) had sore throat. Antiviral (Oseltamivir) was given to $100 \%$ of indoor patients and $6.45 \%$ of outdoor patients. Out of 28 patients admitted, 09 cases were PCR positive and one patient died in hospital who was immunocompromised another one patient died whose PCR test would not done. Early antiviral treatment may have shortened the duration of symptoms and produced better outcome.

\section{Prof. Quazi Tarikul Islam,} FCPS, FRCP, FACP

Professor, Department of Medicine

Dhaka Medical College, Dhaka.

and

Coordinator Swine Flu preparedness team

Dhaka Medical College Hospital

\section{References:}

1. Cumming N,lacobs A, Otterman S. WHO Raises Alert Level as Flu Spreads to 74 Countries. The New York Times. June 11, 2009. Available at: http://www.nytimes.com/ 2009/06/12/worfd/12who.html?_r=2. Accessed 18th December, 2009.

2. Ahasan HAMN. Pandemic (H1N1) 2009 influenza: Bangladesh Perspective. Editorial, J Bangladesh Coll Phys Surg 2009;27;129-131

3. Islam QT. Swine Flu. Editorial. 10 Med July 2009;10;2:3839

4. Institute of Epidemiology, Disease Control and Research Situation of Influenza A H1N1 (Swine Flu). IEDCR;15 December 2009. 